Military Technical College

Kobry Elkobbah, Cairo, Egypt

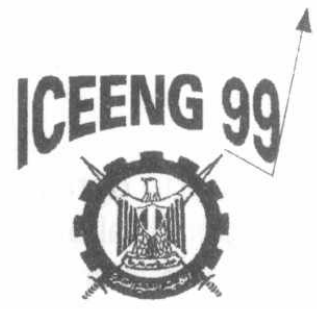

$2^{\text {nd }}$ International Conference on Electrical Engineering ICEENG 99

\title{
Determination of Refractive Index Profile and Material Dispersion of Step Index Optical Fibers using Tow-beam Interferometric Method
}

\author{
M. A. Shanshoul ${ }^{*}$, A.S. Gerges ${ }^{* *}$, EL. A. Mehanna ${ }^{* * *}$
}

\section{ABSTRACT:}

The Pluta polarizing interference microscope is used to measure the refractive index profile and material dispersion of step index optical fiber. the method is explained as well as the theoretical considerations for determination of refractive index. Experimental work is done to measure the refractive index profile of a step index optical fiber at different wavelengths using this technique.

\section{KEY WORDS:}

Engineering physics, Optics, Step Index Optical Fiber, Optical fiber communication, Refractive index profile, Material dispersion.

* P.G.S. Syrian Arab Army.

${ }^{\star \star}$ Assoc. Prof. Dr. Egyptian Army Forces.

*** Assoc. Prof. Dr. Egyptian Army Forces. 


\section{Introduction}

The refractive index profile of the optical fiber core plays an important role in characterizing the properties of the fiber. It allows determination of the fiber numerical aperture, the number of propagation modes within the fiber core and the dispersion of the fiber. So, the detailed knowledge of the refractive index profile enables the impulse response of the fiber to be predicted and consequently the information carrying capacity of the fiber is estimated [1]. The ideal measuring method should satisfy the following conditions: Non destructive, applicable to any profile, high accuracy, high resolution and easy in measurement and data processing.

Different methods were used to determine the fiber's refractive index profile,

some of them [2]: Near field method, X-ray microanalysis, Scanning electron microscope, and Interferometric methods.

Many authors have applied interferometric techniques to determine the optical properties of fibers. Pluta (1972) [3] used his double refracting interference microscope with variable amount and direction of wavefront shear to study the refractive indices and birefringence of synthetic polymer fibers. Hamza and Sikorski (1978)[4] used this microscope to determine the optical anisotropy of Kevlar (poly - $p$ phenylene tereephthalamide) fibers. Hamza (1980)[5] extended the applications of the Pluta microscope to measure the mean refractive indices and birefringence of fibers with irregular transverse sections. Z"urek and Zakrzewski (1983)[6] determined the refractive indices and birefringence of cotton fibers using the Pluta microscope, Hamza et al. [7-10] used Pluta polarizing interference microscope for different fibers with regular and irregular transverse sections to determine their refractive indices and birefringence. Hamza et al. (1994) used this microscope to study the refractive index profiles of cylindrical fiber having core-cladding structure [11].

In classical optics, dispersion is used to denote the wavelength dependence of

refractive index in matter $\left(\frac{d n}{d \lambda}\right)$, where $\mathrm{n}$ is the refractive index and $\lambda$ is wavelength of the light used [12]. In fiber optics communication systems material dispersion means the variation of phase velocities, through the fiber due to many factors, which produces pulse broadening and hence limits the maximum number of pulses a fiber can carry in one second. While in Physics the term dispersion is used to describe the wavelength dependence of refractive index of a given material [13]. This relation is always described by the well-known Cauchy's formula. It is interesting to find the relation between the two terms, which is a part of our interest.

In this paper we used the Pluta microscope to measure the refractive index profile of optical fibers. The basic idea of this technique is explained, and the theoretical consideration for determination of refractive index is given. Then experimental results are obtained for a step index multi-mode optical fiber at different wavelengths. The material dispersion of the fiber is measured.

\section{Theoretical considerations}

\section{a) Determination of refractive index profile of fibers:}

The polarizing interference microscope with a modified method is used to determine the refractive indices and birefringence of both layers of fiber having a 
core-cladding structure [11]. This method is applied to fibers with regular cross section. It can apply also to the fiber with irregular cross section. In this study, the irregularity in the fiber cross-section are dealt with by considering the area enclosed under the fringe shift produced in the microinterferogram represents the optical path difference integrated across the fiber [14].

When a beam of plan polarized monochromatic light is incident on homogeneous fiber, the incident wavefront will be distorted [11]. Figure (1) shows a fiber having a core-cladding structure. The fiber cross section is of radius $\mathrm{R}$ having a cylindrical core surrounding by a cylindrical cladding of thickness $e$. The refractive index of the immersion liquid, the cladding of the fiber and core are $n_{L}, n_{c l}$ and $n_{C}$, respectively. Using the Pluta interference microscope with light of wavelength $\lambda$, the interference fringes suffer shifts as they cross the fiber. The optical path length differences $\Delta$ between the specimen and the immersion liquid are given by [15]:

$$
\Delta=n_{c l} l_{c l}+n_{C} l_{C}-l^{\prime} n_{L}
$$

Where $l_{c l}$ and $l_{C}$ are the path lengths inside the cladding and core of the fiber, respectively, and $l^{\prime}$ is the length of the optical ray through the liquid. $\Delta$ is also given by:

$$
\Delta=\frac{Z}{h} \lambda
$$

Where $Z$ is the interference fringe shift caused by the fiber when the beam crosses it and $h$ is the interfringe spacing. Therefore:

$$
\frac{Z}{h} \lambda=n_{c l} l_{c l}+n_{C} l_{C}-l^{\prime} n_{L}
$$

From figure (1) and the work cited in reference [11], one can obtain the following equation:

$$
\begin{aligned}
& \frac{Z(x) \lambda}{h}=2 n_{c l}\left\{\left[R^{2}-\left(\frac{n_{L} d}{n_{c l}}\right)^{2}\right]^{\frac{1}{2}}-\left[(R-e)^{2}-\left(\frac{n_{L} d}{n_{c l}}\right)^{2}\right]^{\frac{1}{2}}\right\}+2 n_{C}\left[(R-e)^{2}-\left(\frac{n_{L} d}{n_{C}}\right)^{2}\right]^{1} \\
& -n_{L}\left[\left(R^{2}-d\right)^{\frac{1}{2}}+\left(R^{2}-x^{2}\right)^{\frac{1}{2}}\right]
\end{aligned}
$$

$$
0 \leq d \leq R
$$

Where $Z(x)$ is the fringe shift at a distance $x$ from the fiber center, $d$ is the distance between the incident beam and the origin of the fiber, If the incident beam is passing through only in the range $R \succ d \geq(R-e)$, the refractive index is constant $\left(n_{c l}=n_{C}\right)$ and equation $\{4\}$ take the form [11]:

$$
\begin{gathered}
\frac{Z(x) \lambda}{h}=2 n_{c l}\left[R^{2}-\left(\frac{n_{L} d}{n_{C}}\right)^{2}\right]^{\frac{1}{2}}-n_{L}\left[\left(R^{2}-d^{2}\right)^{\frac{1}{2}}+\left(R^{2}-x^{2}\right)^{1}\right] \\
R \succ d \geq(R-e)
\end{gathered}
$$


Proceedings of the $2^{\text {nd }}$ ICEENG Conference, 23-25 Nov. 1999 \begin{tabular}{|l|l|}
\hline $\mathrm{AC}-4$ & 4 \\
\hline
\end{tabular}

Equation $\{5\}$ was derived elsewhere [11] in the case of a homogeneous refractive index fiber. When $e=0$ and $\mathrm{n}_{\mathrm{cl}}=\mathrm{n}_{\mathrm{C}}$.

Using the equation ( 4 and 5 ) one can determine the refractive index profile of the optical fiber from the data taken from the interferogram .

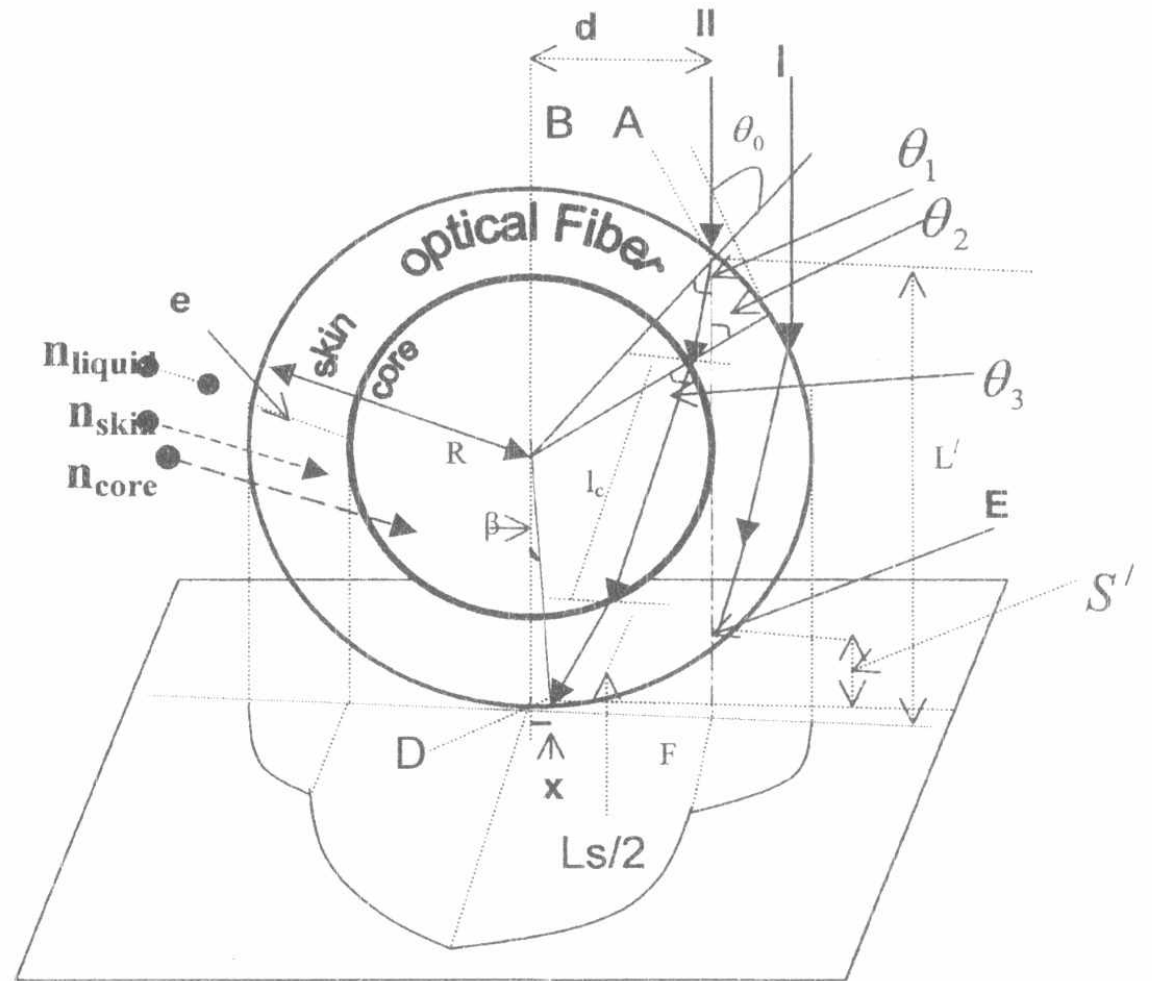

Figure(1)

Core-Cladding fiber which refracting a ray incident at a distance $d$ from the fiber center and the resulting shift in case of two- beam interference [11].

\section{b) Material Dispersion}

A mathematical formulas was derived [16] for the shape of two-bieam interference fringes crossing a cylindrical multi-layer fiber, immersed in a liquid of refractive index $n_{L}$ and have $m$ layer fibers of refractive indices $n_{1}, n_{2} \ldots n_{m}$ where $n_{1}$ is the refractive index of the outer layer and $n_{m}$ is that of the inner layers (core).

$\left(\frac{\lambda}{2 h}\right) d=\sum_{Q=1}^{M}\left(n_{Q}-n_{Q-1}\right)\left(r_{Q}^{2}-x^{2}\right)^{\frac{1}{2}} \quad Q=1,2,3, \mathrm{~m}$

Equation $\{6\}$ gives the shape of the interference fringes where the fringe shift $d$ is related to the value of $x$ along the radius of the fiber, the refractive index $n_{Q-1}=n_{L}$ when $Q=1$. Also $\lambda$ is the wavelength of monochromatic light, $h$ is the interfering spacing, and $r_{Q}$ values of the radii of layers and is given by [16]:

$$
r_{Q}=\left(y^{2}-x^{2}\right)^{\frac{1}{2}}
$$


Figure (2) shows the shape of interference fringes obtained to calculate the refractive index of cladding and core of fiber of unknown refractive indices $n_{\mathrm{Cl}}$ and $n_{C}$ which immersed in a liquid of refractive index $n_{L}$ equation (6) takes the following forms at $\mathrm{x}=\mathrm{r}_{\mathrm{C}}$ and $\mathrm{x}=0$, respectively $[16]$ :

$\left(\frac{\lambda}{2 h}\right) \mathrm{d}_{\mathrm{cl}}=\left(n_{c l}-n_{L}\right) \mathrm{r}_{S C}$

$\left(\frac{\lambda}{2 h}\right) d_{0}=\left(n_{c l}-n_{L}\right) r_{c l}+\left(n_{C}-n_{c l}\right) r_{C}$

Where $r_{c l C}=\left(r_{c l}^{2}-r_{C}^{2}\right)^{\frac{1}{2}}$.

Where $\lambda$ is the wavelength of monochromatic light, $h$ is the interfringe spacing, $r_{c l}, r_{C}$ are the radii of cladding and core, respectively, $\mathrm{d}_{c l}$ is the fringe shift in cladding area, $d_{0}$ is the fringe shift in core area [16]. Cauchys dispersion formula of the fiber is $n_{a}=a+\frac{b}{\lambda^{2}}$

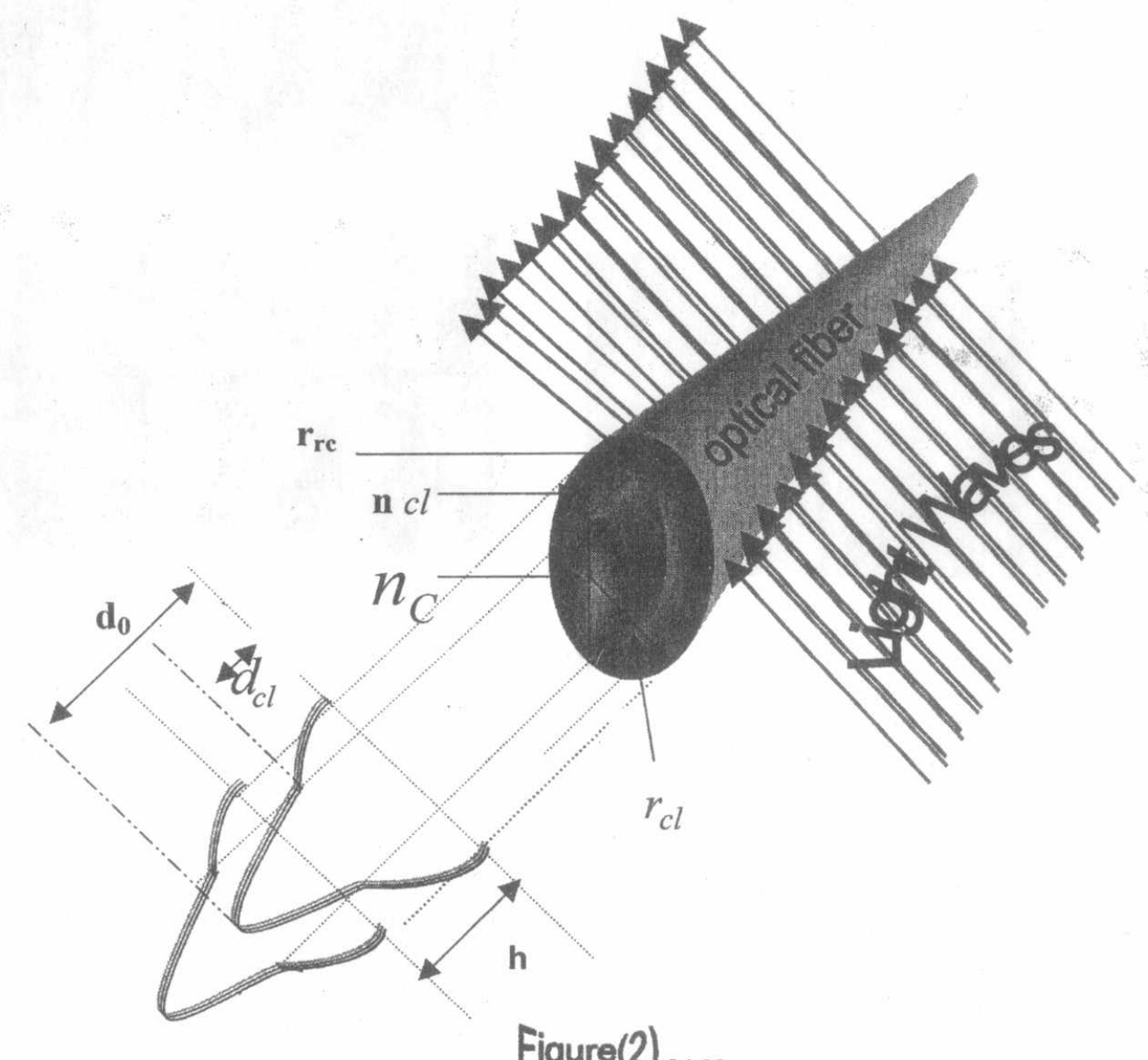

Figure(2) $[16]$ 


\section{Experimental Results}

A multimode step index optical fiber [Ge-B doped $\mathrm{SiO}_{2}\left(r_{\text {core }}=10.8 \mu \mathrm{m}\right)$ Diameter $24 \mu \mathrm{m}$ ] is used to show the effect of refraction of the light beam by the fiber in the case where difference between the fiber cladding and core refraction indices is detectable. The fiber is placed on a microscope slide and, its ends are fixed to the slide so that the fiber is immersed in a liquid and a cover slip is placed on the iber. The objective prism of the Pluta polarizing interference microscope is rotated to cobtain maximum duplication of the two images of the fiber [16]. Then the slit diaphragm is rotated to make a suitable angle with the fiber axis to obtain the sharpest fringes. Micronterferograms has been registered by a camera fixed to the microscope to show the effect of variation of refractive index of the fiber with wavelength. These microinterferograms are shown in figure (3) which are obtained using wavelengths $546 \mathrm{~nm}, 550 \mathrm{~nm}, 577 \mathrm{~nm}$ and $590 \mathrm{~nm}$, respectively. Special computer software [11] is used to determine the refractive index profile of the optical fiber from the data taken from the interferogram.
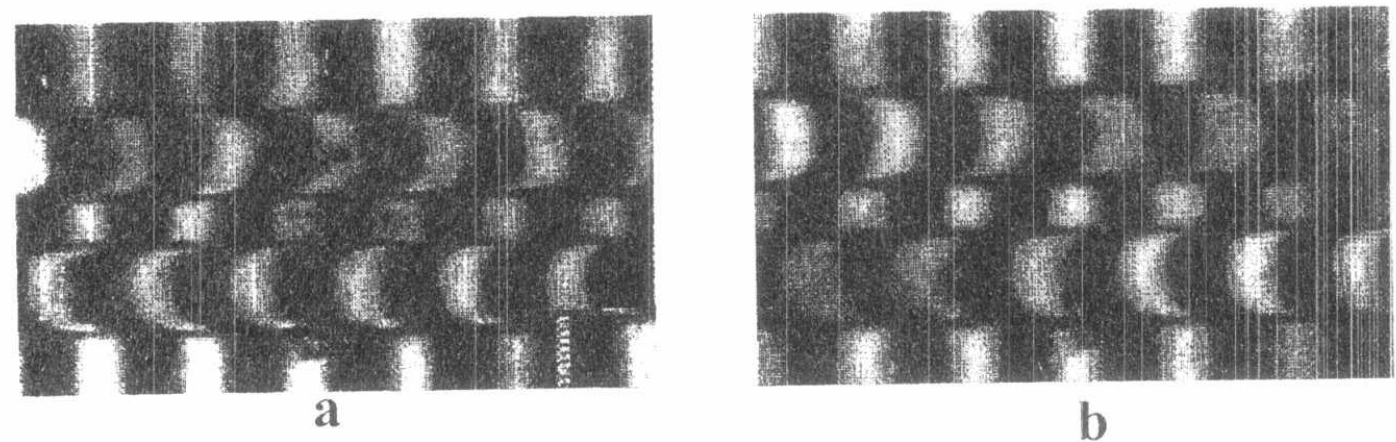

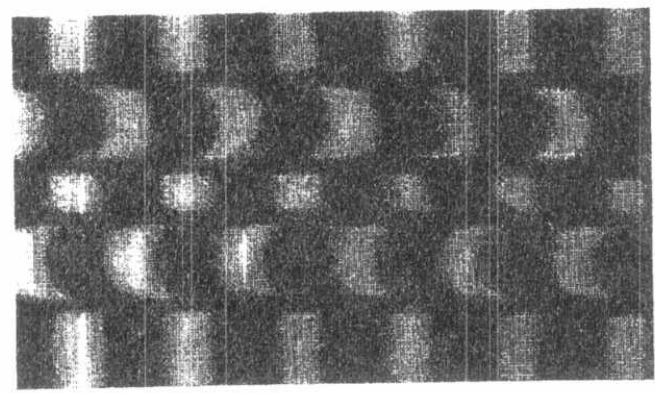

C b

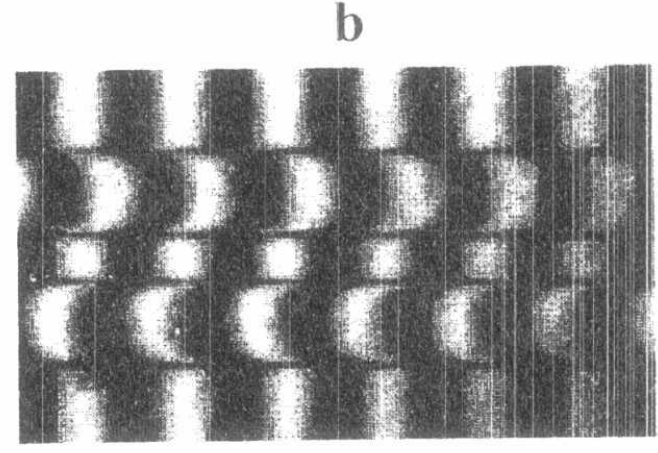

d

Figure(3)

Interferograms using the wavelength: a) $\lambda=546 \mathrm{~nm}$, b) $\lambda=550 \mathrm{~nm}$, c) $\lambda=577 \mathrm{~nm}$ and d) $\lambda=590 \mathrm{~nm}$.

The calculated refractive index profiles are shown in figures (4), (5), (6) and (7), and the accuracy of the refractive index is about $\mp 0.001$. These figures represent the refractive index profiles at different wavelength. Every one consists of two parts, one at the middle, which represent the refractive index profile in the core of fiber but the two small edge of the curves represent refractive index profile of the cladding. 


\begin{tabular}{|l|l|}
\hline $\mathrm{AC}-4$ & 7 \\
\hline
\end{tabular}

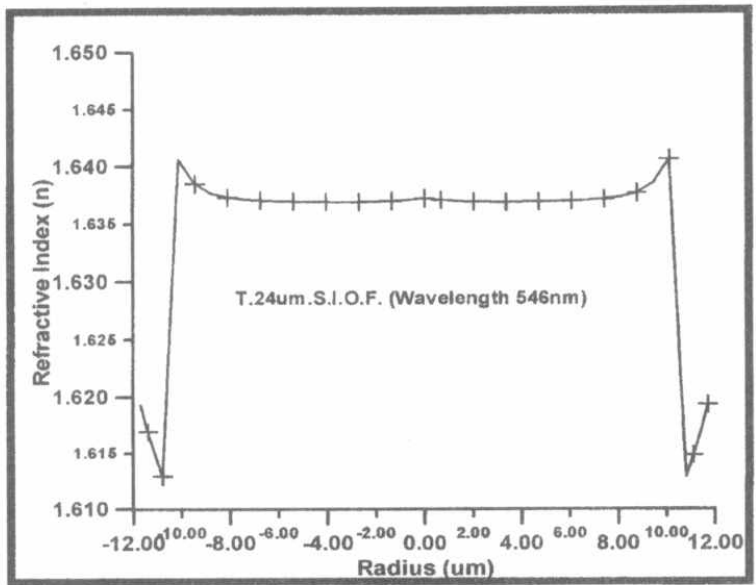

Figure(4)

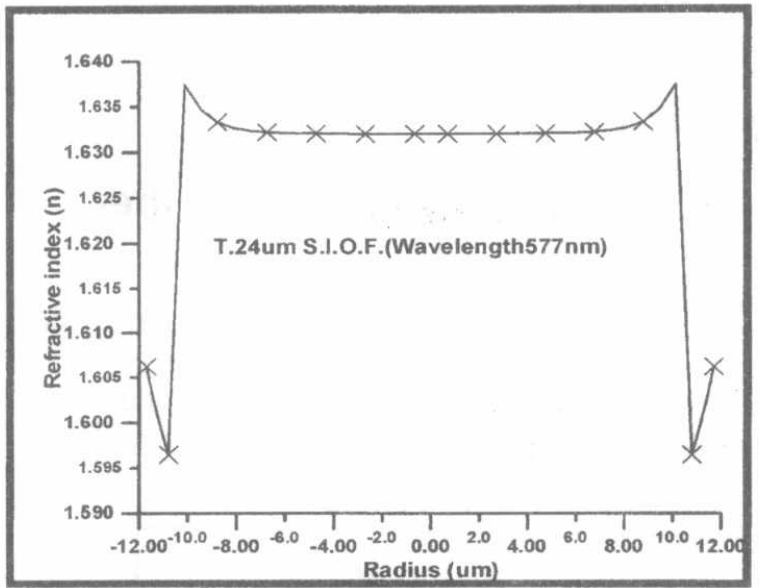

Figure (6)

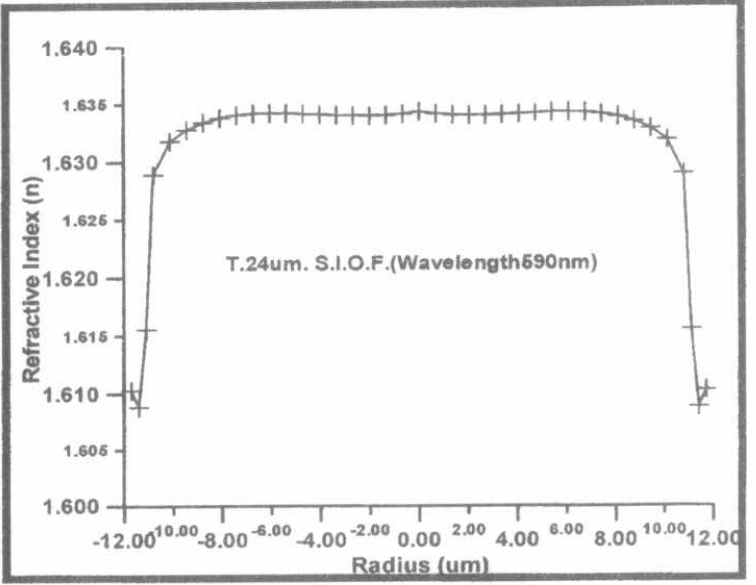

Figure(5)

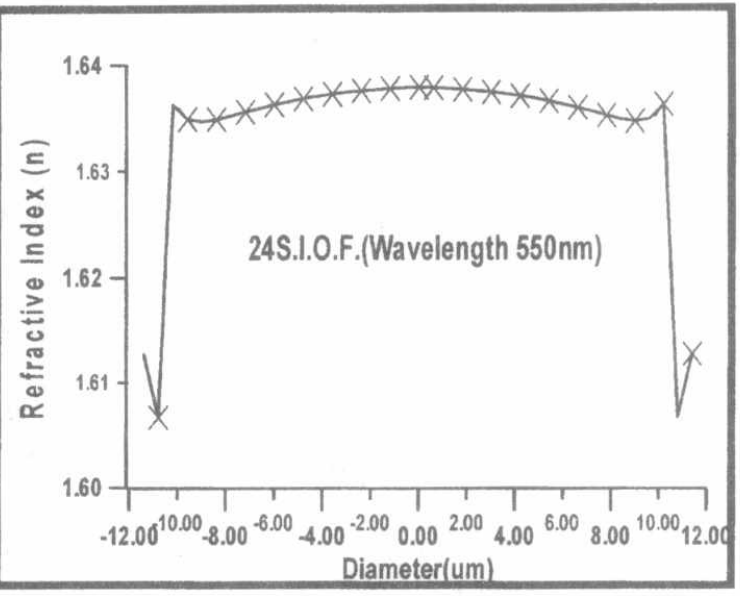

Figure(7)

constant (at the same wavelength) but is different from wavelength to another.

Using equations $\{8$ and 9$\}$ and microinterferograms $n_{c l}$ and $n_{c}$ are calculated, then material dispersion of the fibers is studied. The variation of refractive index $n$ at the fiber center with wavelengths are tabulated in table (1), and figure (8) shows the spectral dispersion curve for the core of step index optical fiber,

\section{Table(1)}

\begin{tabular}{|c|c|}
\hline Wavelength $\mathbf{n m}$ & $\mathbf{n}(\lambda)$ \\
\hline 546 & $1.638 \pm 0.001$ \\
\hline 550 & $1.637 \pm 0.001$ \\
\hline 577 & $1.636 \pm 0.001$ \\
\hline 590 & $1.635 \pm 0.001$ \\
\hline
\end{tabular}




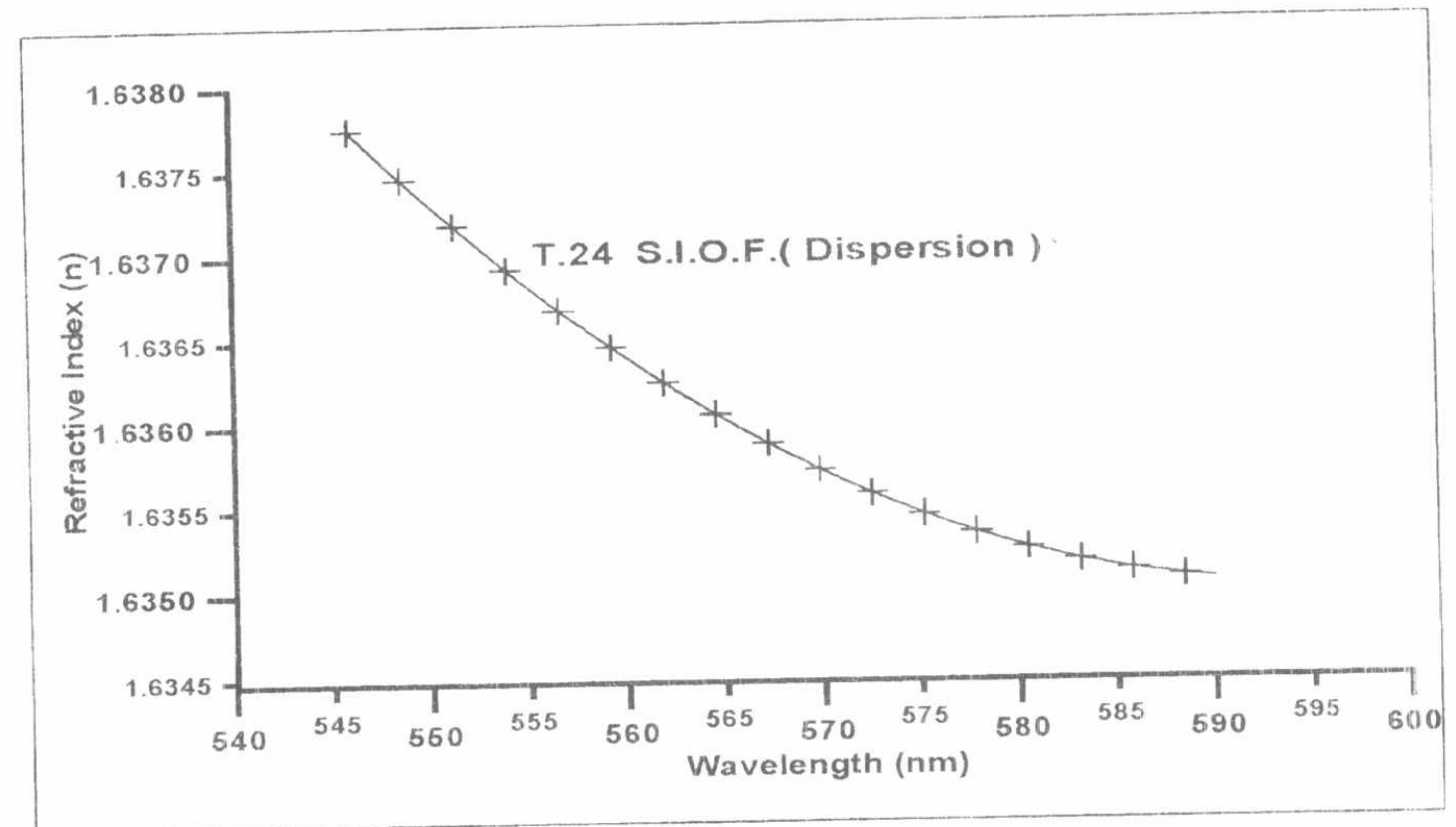

Figure(6)

\section{The Spectral Dispersion Curve of Step Index Optical Fiber}

While this varıation of refractive index $(n)$ with $\frac{1}{\lambda^{2}}$ is shown in figure (9). From figure (9) it is clear that it follows the Cauchy's formula ( equation 10). The Cauchy's constants is calculated and found, $a=1.6352, b=6188.0893\left(\mathrm{~nm}^{-2}\right)$.

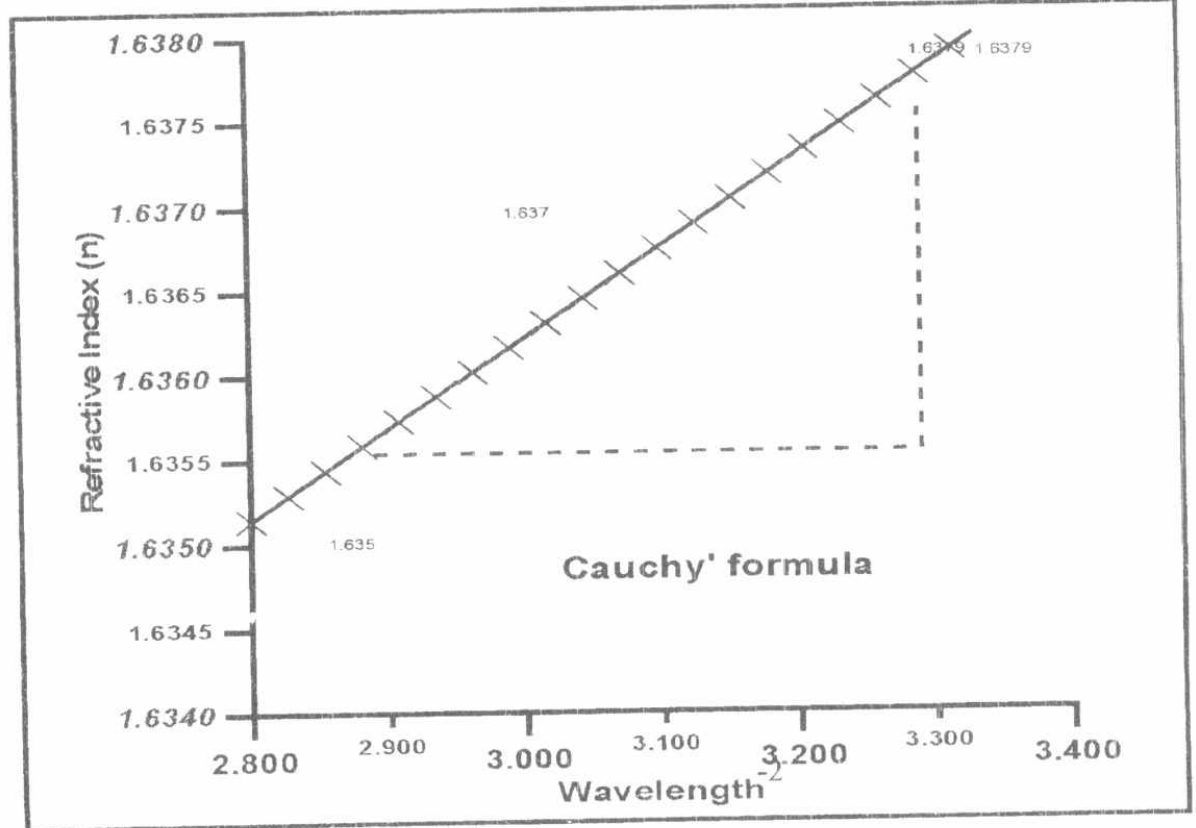

Figure(9) 
Proceedings of the $2^{\text {nd }}$ ICEENG Conference, 23-25 Nov. 1999

\begin{tabular}{|l|l|}
\hline $\mathrm{AC}-4$ & 9 \\
\hline
\end{tabular}

\section{Conclusion}

A sample of step index optical fiber was used to study the effect of refraction of the light beam by the fiber and the effect of mismatching in the case of a corecladding fiber. The refractive index profiles were measured experimentally using twobeam interference microscopy. This technique uses Pluta polarizing interference microscope to determine the refractive index profile of core-cladding fiber. We conclude from the results that the refraction of the beam inside the fiber is to be taken into consideration especially when there is a great difference in the refractive indices of the fiber and the immersion liquid. We recommend using an immersion liquid with refractive index close to that of the fiber especially in the case of core-cladding fiber structure.

\section{Acknowledgement:}

The authors would like to express their greatest gratitude to Prof. Dr. Ahmed Amin Hamza, Professor of Physics, and President of Mansoura University for useful discussions, guidance and helpful advice to complete this work.

Thanks also to Prof. Dr. Taha Zakky NabawySokkar, Professor of Physics; Faculty of Science, Mansoura University, and Dr. Mohamed Mabrouk, Assoc.Prof.of Physics, Faculty of Science, Mansoura University, Damieta, for their valuable support .

\section{References:}

1- M. John Senior,"Optical Fiber Communication (principles and practice)",Prentice- Hall International, Inc. London. P 202. (1986).

2-N. Barakat, A.A. Hamza . "Interferometry of Fibrous Materials", Adam Hilger. P114. (1990).

3- M.,Pluta, J.Microscopy, Vol.96,P.309,(1972).

4-A.A. Hamza and Sikorski J.Microsc.Vol. 113,P15.(1978)

5- A.A. Hamza, TextileRes. J.Vol. 50, P731 (1980).

6- W. Z"urek and S. Zakkrzewski J.Appl. polym. Sci.Vol. 28,P 1277, (1983).

7-A.A. Hamza, The Journal of Microscopy, Vol.142, P. 35. (1986)

8- A.A. Hamza and HI Abd El-Kader Phys.Ed.Vol.21,P244, (1986).

9- A.A. Hamza and K A. EL- Farahaty, TextileRes. J.Vol. 56, P580 (1986)

10- A.A. Hamza and T. EL-Dessouki, TextileRes. J.Vol. 57, P508 (1987).

11-A.A. Hamza, A.M. Ghander, T.Z.N. Sokkar, M.A. Mabrouk, and W. A. Ramadan, Pure and Appl.Optics, P943-961. (1994).

12-B.E.A. Saleh, M.C. Teich, "Fundamental of Photonics", John Wiley \& Sons, Inc.(1991).

13- Henry Zanger " Fiber Optics (communication and other applications) by Macmillan Publishing Company, P,58. (1991).

14-S.C. Simmens, Nature P.181, (1958).

15- A.A. Hamza, T.Z.N. Sokkar and M.A. Kabeel, J.Phys.D:Appl.Phys. V18, P.2321, (1985)

16- A.A. Hamza, T.Z.N. Sokkar, and M. M. Shahin . J.Appl. Phys. V 10, P. 69(1991). 
